\title{
Novel Influenza AH1N1 (Swine Flu)
}

\author{
Sri Lanka Journal of Child Health, 2009; 38: 83-85
}

(Key words: Swine Flu, Novel Influenza AH1N1 virus)

'Swine flu' refers to disease caused by strains of influenza virus that usually infect pigs ${ }^{1}$. Transmission of swine flu virus from pigs to humans is uncommon and does not always cause human influenza, often only resulting in the production of antibodies in the blood $^{1}$. People working with pigs, especially those with intense exposure, are at risk of catching swine flu ${ }^{1}$.

The 2009 swine flu outbreak in humans is actually due to a new strain of influenza A virus subtype H1N1 (Novel Influenza AH1N1) that contains genes closely related to swine influenza ${ }^{2}$. The origin of this new strain is unknown. However, the World Organization for Animal Health reports that this strain has not been isolated in pigs ${ }^{3}$. This strain can be transmitted from human to human ${ }^{4}$.

The 2009 flu pandemic ${ }^{5}$ is a global outbreak of Novel Influenza AH1N1, identified in April 2009, which infects and is transmitted between humans. It is thought to be a mutation, or more specifically, a reassortment of four known strains of influenza A virus subtype H1N1: one endemic in humans, one endemic in birds, and two endemic in pigs (swine) ${ }^{6}$. A July 6 , 2009 update by the World Health Organization (WHO) states that the world's pandemic flu total has reached 94,512 cases, 429 of them fatal ${ }^{7}$. The WHO officially declared the outbreak to be a pandemic on June 11 , but stressed that the new designation was a result of the global spread of the virus, not its severity which can be mild, moderate, or severe. The case fatality rate (CFR) of the pandemic strain is estimated at $0.4 \%$ (range $0.3 \%-1.8 \%)^{8}$.

In Sri Lanka, the Healthcare and Nutrition Ministry follows WHO recommendations when handling suspected cases of Novel Influenza AH1N1. The monitoring system is carried out at the Bandaranaike International Airport where 40 Public Health Inspectors (PHIs) work on a shift basis ${ }^{9}$. The Ministry has allocated 20 sentinel hospitals in 20 districts to treat the disease and has also obtained the required antiviral drugs, medical equipment and masks from the $\mathrm{WHO}^{9}$. At present, all suspected cases of Novel Influenza AH1N1 are admitted to the Infectious Disease Hospital (IDH) situated at
Angoda. Up to 31 st July 2009, the total number of persons found positive for Novel Influenza AH1N1 was 60 and there were no fatalities ${ }^{9}$. However, in neighbouring India, 1927 laboratory confirmed cases of Novel Influenza AH1N1 have been reported up to $17^{\text {th }}$ August 2009 with 25 deaths ${ }^{10}$. Hence, one should not be too complacent about the current situation in Sri Lanka and all unnecessary travel to India should be curtailed.

The estimated incubation period is unknown and could range from 1 to 7 days, although the incubation period for most cases will likely range from 1 to 4 days $^{11}$. The duration of shedding for the novel H1N1 virus is unknown. Infected persons are assumed to be shedding virus from the day prior to onset of illness until resolution of symptoms ${ }^{11}$.

The symptoms of infection with Novel Influenza AH1N1 are similar to other forms of influenza, and include fever, cough, headache, pain in the muscles or joints, sore throat, chills, fatigue and runny nose. Diarrhoea and vomiting have also been reported in some cases ${ }^{12}$. A study published in the New England Journal of Medicine, found that $94 \%$ of confirmed patients had fever and $92 \%$ had cough ${ }^{13}$.

The virus typically spreads from coughs and sneezes or by touching a surface contaminated with flu viruses and then touching the eyes, nose, or mouth ${ }^{14}$. The U.S. Centers for Disease Control and Prevention (CDC) advised avoiding such contact and frequent washing of hands with soap and water or with alcohol-based hand sanitizers, especially after being out in public. Those coughing should use a tissue, dispose of the tissue and then wash hands right away ${ }^{14}$. Transmission was also reduced by disinfecting household surfaces with a disinfectant or a diluted bleach solution ${ }^{15}$.

The virus is a novel strain of influenza. Existing vaccines against seasonal flu provide no protection, and there is no vaccine for this strain. WHO DirectorGeneral Margaret Chan says that it will probably be September 2009 before the first doses of a vaccine for the 2009 flu pandemic strain will become available and even then, "there will be limited supply 
of vaccine" ${ }^{15}$. There is concern that the virus could mutate later in the year and become more virulent and less susceptible to any vaccine developed to protect from an earlier strain ${ }^{16}$.

Up until May 24, 2009 nearly 90\% of reported deaths had taken place in Mexico. This has led to speculation that Mexico may have been in the midst of an unrecognized epidemic for months prior to the current outbreak, thereby showing a fatality rate that was much higher than it would have been if earlier cases had been counted ${ }^{17}$. According to the U.S. Centers for Disease Control and Prevention (CDC), the fact that the flu's infection activity is now monitored more closely may also help explain why more flu cases than normal are being recorded in many countries ${ }^{16}$.

The Mayo Clinic suggested a number of measures to help ease symptoms, including adequate hydration and rest, soup to ease congestion, and over-thecounter drugs to relieve pain ${ }^{18}$. In general, most patients were expected to recover without requiring medical attention, with the exception of individuals with pre-existing or acquired complications ${ }^{19}$.

Should all children with suspected or confirmed infection with novel influenza AH1N1 be treated with antiviral pharmacotherapy? If a child is not in a high-risk group or is not hospitalized, CDC guidelines recommend using clinical judgment to guide treatment decisions ${ }^{20}$. A child with mild disease, who is not in a high-risk group may not significantly benefit from drug therapy, especially if pharmacotherapy is not initiated early.

Risk factors for complications and increased disease morbidity from novel influenza $\mathrm{AH} 1 \mathrm{~N} 1$ are similar to infection and disease from seasonal influenza. Children younger than 5 years of age, and especially children younger than 2 years, are at higher risk of complications. Concomitant diseases that increase risk of complications from novel influenza AH1N1 include immune suppression, HIV/AIDS, chronic kidney disease, heart disease, diabetes mellitus, asthma/pulmonary disorders, haematologic disorders, neurologic disorders affecting respiratory function, metabolic disorders and children receiving long-term aspirin therapy ${ }^{19}$.

Only two antiviral agents are recommended by the CDC for treatment of novel influenza AH1N1 disease viz. oseltamivir (Tamiflu) and zanamivir ${ }^{18}$. These two agents are both neuraminidase inhibitors. Viral enzyme neuraminidase functions to detach newlyproduced virus from the host cell, preventing its release to infect other cells. This drug's mechanism of action explains why these agents are most effective when given early in the disease process when viral replication is high $^{19}$. The 2009 novel influenza $\mathrm{AH} 1 \mathrm{~N} 1$ virus is resistant to amantadine and rimantadine. The $\mathrm{CDC}$ has noted that as the flu pandemic spreads these antiviral drugs might become in short supply. Therefore, the drugs should be given first to those people who have been hospitalized or are at high risk of complications. The drugs work best if given within 2 days of becoming ill, but might be given later if illness became severe or to those at a high risk for complications ${ }^{19}$. Recommended duration of treatment is 5 days ${ }^{11}$.

Cases of novel influenza AH1N1 that were resistant to the antiviral drug oseltamivir (Tamiflu) have now been found in the United States, Canada, Denmark, Hong Kong and Japan ${ }^{20}$. Resistant strains were probably emerging because of overuse of this drug.

For antiviral chemoprophylaxis of novel H1N1 infection, either oseltamivir or zanamivir is recommended $^{11}$. Duration of chemoprophylaxis postexposure is 10 days after the last known exposure to an ill, confirmed case of novel H1N1 infection ${ }^{11}$. For pre-exposure protection, chemoprophylaxis should be given during the potential exposure period and continued for 10 days after the last known exposure to an ill, confirmed case of novel H1N1 infection ${ }^{11}$. Antiviral chemoprophylaxis is recommended for children below 5 years of age who are household contacts of a confirmed case of novel H1N1 infection $^{11}$.

\section{References}

1. Swine influenza. From Wikipedia, the free encyclopedia. Available from: http://en.wikipedia.org/wiki/Swine_influenza

2. V Trifonov, H Khiabanian, B Greenbaum, R Rabadan. "The origin of the recent swine influenza A(H1N1) virus infecting humans". Eurosurveillance 2009; 4(17): Available from:

http://www.eurosurveillance.org/images/dyn amic/EE/V14N17/art19193.pdf.

3. Maria Zampaglione (April 29, 2009). "Press Release: A/H1N1 influenza like human illness in Mexico and the USA: OIE statement". World Organisation for Animal Health. Available from: http://www.oie.int/eng/press/en 090427.htm 
4. Swine influenza World Health Organization 27 April 2009. Available from: http://www.who.int/mediacentre/news/state ments/2009/h1n1 20090427/en/index.html

5. "WHO: Swine flu pandemic has begun, 1st in 41 years". The Associated Press. June 11, 2009. Available from:

http://www.google.com/hostednews/ap/articl e/ALeqM5jTkkEKE5LtPih_5Jcc3MpD0gO YQD98OH0U00.

6. "Deadly new flu virus in U.S. and Mexico may go pandemic". New Scientist. April 28, 2009. Available from:

http://www.webcitation.org/5gNd9HTT9

7. Pandemic (H1N1) 2009 - update 58 (6 July 2009 09:00 GMT). Laboratory-confirmed cases of pandemic (H1N1) 2009 as officially reported to WHO by States Parties to the International Health Regulations (2005)". Available from:

http://www.who.int/csr/don/2009 07 06/en/ index.html

8. Fraser, Christophe; et al. (June 2009). "Pandemic Potential of a Strain of Influenza A (H1N1): Early Findings" (PDF). Science 324 (5934): 1557-1561. Available from: http://www.sciencemag.org/cgi/reprint/324/ 5934/1557.pdf

9. Gunatilleke N. AH1N1: Contacts with patients infected seven. Sixty found positive here. Available from:

http://www.dailynews.lk/2009/08/04/news2

$\underline{8 . a s p}$

10. Swine Flu India: Latest updates, alerts, precautions, prevention. Available from: http://www.swineflu-india.org/

11. Novel H1N1 Novel Influenza (Swine Flu). Available from:

http://www.cidrap.umn.edu/cidrap/content/i nfluenza/swineflu/biofacts/swinefluovervie w.htm

12. Centers for Disease Control and Prevention (CDC) article Interim Guidance for H1N1 Flu (Swine Flu): Taking Care of a Sick Person in Your Home updated regularly. Available from: http://www.cdc.gov/h1n1flu/guidance home care.htm
13. Emergence of a Novel Swine-Origin Influenza A (H1N1) Virus in Humans. New England Journal of Medicine, 2009; 360 (25): 2605-15. Available from: http://content.nejm.org/cgi/reprint/NEJMoa0 903810v3.pdf

14. US Centers for Disease Control. "Infection Control Guidance for the Prevention and Control of Influenza in Acute-Care Facilities". Available from: http://www.cdc.gov/flu/professionals/infecti oncontrol/healthcarefacilities.htm

15. "Declaration Of H1N1 Pandemic To Accelerate H1N1 Vaccine Production". Medical News Today. Kaiser Foundation. 15 June 2009. Available from: http://www.medicalnewstoday.com/articles/ 153900.php.

16. Anne Schuchat (26 May 2009). "Press briefing May 26, 2009, 1 pm ET". Centers for Disease Control and Prevention. Available from:

http://www.cdc.gov/media/transcripts/2009/t 090526.htm.

17. "Flu's true severity is still unknown". Washington Post. 2 May 2009. Available from:

http://www.washingtonpost.com/wpdyn/con tent/article/2009/05/01/AR2009050101777. $\underline{\mathrm{html}}$.

18. Mayo Clinic Staff. "Influenza (flu) treatments and drugs". Diseases and Conditions. Mayo Clinic. Available from: http://www.mayoclinic.com/health/influenza /DS00081/DSECTION=treatments-and drugs.

19. "What to do if you get flu-like symptoms". Centers for Disease Control and Prevention. 7 May 2009. Available from: http://www.cdc.gov/h1n1 flu/sick.htm.

20. Treatment resistant swine flu detected in US. Available from:

http://ca.news.yahoo.com/s/afp/090804/healt h/health flu world 204
G N Lucas

Joint Editor 

